\title{
Contra el ciberutopismo. \\ Discurso utópico versus análisis sociológico \\ sobre la transición \\ al paradigma digital de la esfera cultural
}

\author{
Joaquim Rius-ULLDEMOLINS \\ Universitat de València \\ joaquim.rius@uv.es
}

Recibido: 29-05-2014

Aceptado: 18-02-2015

\section{Resumen}

La cultura ha dejado de ser la esfera social que iluminaba la modernidad. A pesar de su mayor centralidad social y económica propia de la sociedad postfordista, las transformaciones económicas y tecnológicas de los últimos años están cuestionando su propia existencia como esfera autónoma. En este contexto, el discurso del ciberutopismo hace una lectura totalmente positiva de estas transformaciones como un empoderamiento del consumidor o del surgimiento de nuevas cadenas de cooperación creativa. Frente a este discurso ideológico, es necesaria una ruptura epistemológica y la construcción de un programa de investigación desde la sociología de las artes y la cultura, que evalúe de forma crítica y distanciada los efectos reales de la transición a lo digital y sus efectos. Estos, lejos de ser completamente positivos, pueden conllevar un empobrecimiento del consumo y la creación cultural y conducir a un escenario de dominio oligopólico del sector cultural por parte de las grandes corporaciones tecnológicas.

Palabras clave: paradigma digital, esfera cultural, ciberutopismo, ciberfetichismo, comunidad, consumo cultural, oligopolización. 


\title{
Against Cyber-Utopianism. \\ Utopian Discourse versus Sociological Analysis \\ of the Transition to the Digital Paradigm of the Cultural Sphere
}

\begin{abstract}
Culture is no longer the social sphere that illuminated modernity. In spite of its greater social and economic centrality centrality characteristic of postfordist society, economic and technological changes in recent years are questioning their existence as an autonomous sphere. In this context, the discourse ciberutopist takes a totally positive reading of these transformations as an empowerment of the consumer or the emergences of new chains of creative cooperation. Against this ideologically loaded discourse, it's necessary an epistemological rupture and a construction of a research program from the sociology of culture, to evaluate critically and neutral the actual effects of the transition to digital paradigm and its effects. These, far from being completely positive, may incur an impoverishment of cultural consumption and creativity and lead to a scenario of oligopolistic dominance cultural sector by large technology corporations.
\end{abstract}

Keywords: Digital Paradigm; Cultural Sphere; Cyber-utopianism; Cyber-fetishism; Community; Cultural Consumption; Oligopolization.

\section{Referencia normalizada}

Rius-Ulldemolins, J. (2015): “Contra el ciberutopismo. Discurso utópico versus análisis sociológico sobre la transición al paradigma digital de la esfera cultural", Política y Sociedad, 52 (1), pp. 153-178.

Sumario: 1. Introducción. 2. La ideología californiana, el ciberfetichismo y los cambios culturales. 3. La comunidad de consumo y producción cultural en el entorno digital. ¿Unos nuevos patrones de sociabilidad y creación? 4. ¿Una destrucción creativa para los intermediarios sector cultural o un proceso de oligopolizacion creciente? Aportaciones de la sociología de la cultura. 5. ¿El Crowdsourcing: pilar de un nuevo sistema cultural? 6. Conclusiones. 7. Bibliografía. 


\section{Introducción}

Desde la irrupción de lo que llamamos internet, el futuro en el mundo cultural ${ }^{1}$ ya no es lo que era. Ciertamente, hace tiempo que los mundo del arte han dejado de ser una esfera social - en términos weberianos - que anunciaba la llegada de la modernidad y a la vez se convertía en una esfera crecientemente autorreferencial y autónoma (Bourdieu 1977). En la época dorada de la modernidad artística, desde finales del siglo XIX hasta mediados del siglo XX, el mundo artístico tuvo una acentuada influencia sobre la esfera política y económica, tal y como señaló Daniel Bell (2007). Por el contrario, desde la irrupción de la sociedad posfordista y sus dinámicas posmodernas (Bell 1976, Jameson 1986), si bien la cultura ha ganado una posición central, al mismo tiempo ha dejado de constituir una esfera social en la que otras esferas sociales se inspiran. Y de forma progresiva está quedando bajo el influjo —o la dominación - de otras esferas como la economía y la tecnología, siendo ésta última uno de los vectores que mayores transformaciones está produciendo con la transición hacia lo digital. Una proceso que aún no conocemos qué consecuencias puede traer para la esfera cultura y su relación con otras esferas pero que es objeto de un discurso tecnológico y utopista, el ciberutopismo. ${ }^{2}$ En cierta medida, podemos afirmar como señala Jaron Lanier, que el futuro de la cultura (o el discurso sobre él) "ya no nos pertenece" porque ha sido secuestrado por un discurso que sitúa la tecnologización de la sociedad y la cultura como único horizonte posible y a la inteligencia colectiva como el agente promotor de los cambios sociales y culturales (Lanier, 2013). Un discurso que invade cada vez más las formas de percibir y comprender la esfera cultural, desarticulando la defensa humanística sobre el valor cultural intrínseco, el llamado art's for art sake.

Así pues, actualmente existe un discurso dominante que cuestiona las instituciones, cadenas cooperativas y mecanismos de asignación de recursos de la cultura, que constituyen su base organizativa e institucional de la cultura. Y se insiste en la necesaria reconfiguración de los paradigmas clásicos de producción, distribución y consumo

\footnotetext{
${ }^{1}$ Somos conscientes de que existen diferentes definiciones de cultura. En este artículo utilizaremos la definición sociológica de cultura, es decir, la que hace referencia al campo especializado de las artes y su relación con la sociedad (Ariño, 1997). No abordaremos en este artículo el impacto del ciberfetichismo en otras dimensiones del término cultura —en su sentido más amplio y antropológico- como la educación o la investigación, aspecto que han abordado otros autores (Ariño, 2009).

${ }^{2}$ Ciberutopismo es un término originalmente acuñado por Eugeny Morozov (2012) - ver nota $2-\mathrm{y}$ etimológicamente es producto de la contracción entre utopismo, la voluntad de construir una sociedad ideal, y de la palabra cyber. La cibernética es la ciencia de la regulación y de la optimización del control y de la comunicación. Esta ciencia se centra en las máquinas y en su capacidad de analizar información y en su habilitad de tomar decisiones de forma autónoma (Ouellet, 2009). Por lo tanto, el ciberutopismo vendría a referirse a una supuesta idealización extrema de capacidad de la cibernética —y por extensión, de las nuevas tecnologías de la información y la comunicación - de contribuir a la sociedad ideal.
} 
cultural, así como de la articulación y papel entre actores estatales, del mercado y sociales en que estos se sustentan. Parafraseando la famosa frase de Marx, todo lo que parecía sólido en el mundo cultural parece desvanecerse en el aire de la crisis y el tsunami digital.

Frente a este estado de cosas, se perfilan diferentes posiciones ante los cambios actuales reales (o a los cambios futuros imaginables) respecto a lo transición al paradigma digital. Una de estas posiciones, crecientemente dominante, es la que se ha llamado ciberfetichista ociberutópico (Morozov, 2012; Morozov, 2013; Rendueles, 2013). ${ }^{3}$ Este discurso enfatiza el poder transformador de las nuevas tecnologías en lo social, económico, político y en lo cultural, subrayando la dimensión positiva de las formas de cooperación y participación que supuestamente éstas impulsan. Unos cambios que en la esfera cultural comportan la posibilidad de generar un empoderamiento de los consumidores y nuevos procesos creativos sin intermediarios que tengan impactos sociales y políticos positivos y generen nuevos vínculos sociales que compensen la pérdida de capital social característico de las sociedades avanzadas (Putnam, 1995).

Este discurso, más que una descripción de la realidad es un discurso utópico (o distópico según se mire) y en realidad sobreestima el poder de transformación de las nuevas tecnologías y las convierte en un fetiche que tiene la capacidad de responder si no a todos a buena parte de los males sociales actuales. Sin embargo, recientemente han surgido discursos críticos con los axiomas y las consecuencias no buscadas de este pensamiento, entre el que se encuentran debilitar las sociabilidades reales y la capacidad de pensar alternativas al sistema actual (Rendueles, 2013). Por lo tanto, desde nuestro punto de vista es necesario realizar una crítica a este discurso y su aplicación a la cultura para repensar el impacto de lo digital en la esfera cultural, evaluar los efectos no deseados como la concentración oligopólica y las posibles alternativas que puedan existir para gobernar estos procesos.

No obstante, uno de los obstáculos al debate sobre la cuestión digital es que habitualmente se desarrolla en los ámbitos no académicos y con conflictos de interés no declarados. Al contrario de lo que se pudiera pensar en un inicio, los fórums presentes en internet no permiten un intercambio de ideas equilibrado, sino que en este ámbito se

${ }^{3}$ El término ciberutopico es utilizado por primera vez por Eugeny Morozov que lo define como "una fe ciega en la naturaleza emancipadora de la comunicación en la red, que descansa sobre una tozuda negativa a reconocer sus inconvenientes" (Morozov 2012: 11). Por otra parte, el filósofo español Cesar Rendueles, estableciendo un paralelismo entre el concepto marxista de fetichismo y el discurso utópico sobre internet ha acuñado la palabra ciberfetichismo (Rendueles 2013). En este artículo utilizaremos indistintamente los dos conceptos, al entender que los dos hacen referencia fundamentalmente al mismo fenómeno: un discurso que sobre-evalúa la naturaleza positiva de la tecnología y su efecto beneficioso sobre la sociedad y la cultura. Aunque desde luego, otros autores han señalado la fetichización de los discursos sobre la tecnología y sus efectos sociales - como por ejemplo el concepto de sociedad red de Castells y los usos políticos neoliberales del determinismo tecnológico (Ouellet 2009)—, Morozov y Rendueles son los primeros en convertir el discurso ciberutopico-ciberfetichista en un objeto de estudio en si mismo. 
producen enfrentamientos muy ideologizados en los que individuos fanatizados "trolean" los debates amparándose en el anonimato de los fórums digitales.Otro obstáculo al debate sobre el cibertutopismo es que quienes lo defienden, creen realmente estar defendiendo el progreso de la humanidad frente a unas fuerzas reaccionarias (Lessig et al., 2005) ${ }^{4}$ y se somete a los adversarios al escarnio público (Lanier, 2011) o bien lo acusan de ser internet-fóbico (Morozov, 2012). Este carácter de discurso y de creencia ideológica del cibertutopismo dificulta enormemente el debate público y a la vez la investigación empírica. En este artículo plantemos la necesidad de proceder a una ruptura epistemológica en el sentido que lo proponen Bourdieu et al. (1994) con este discurso convertido en dominante en ciertos sectores para posteriormente poder construir de forma racional un objeto y poder desarrollar un programa de investigación que evalúe de una forma neutral los impactos de la transición a lo digital del mundo cultural.

En este artículo analizaremos en primer lugar las raíces del ciberutopismo para, en segundo lugar, adentrarnos en el uso que hace este discurso de la noción de comunidad y sus repercusiones sobre la producción y el consumo cultural. A continuación, en tercer lugar ${ }^{5}$ analizaremos críticamente el discurso sobre la necesaria destrucción de los intermediarios culturales en la era digital. Y finalmente, estudiaremos una de las ideas o proyectos estrella del ciberfetichismo, el crowdsourcing, contrastando los impactos prometidos por este discurso con la realidad actualmente existente, lo que nos dará una idea de la distancia entre los dos elementos. Finalmente, haremos un balance de las aportaciones y los riesgos del discurso como herramienta para analizar las transformaciones de la esfera cultural y de la posibilidad de gobernar el tránsito hacia el paradigma digital.

\footnotetext{
${ }^{4}$ Podríamos poner numerosos ejemplos internacionales y nacionales de este tipo de discurso que emplea una retórica de amigo / enemigo y que sitúa a un lado los que están a favor de internet, el progreso y la verdad y al otro lado y de forma estereotipada, las fuerzas "analógicas", la reacción y la ocultación. Por ejemplo, en sus libros Lessig hace un llamamiento a la movilización popular para denunciar la captura de la cultura libre como una de las luchas más importantes de la época (Lessig et al., 2005). Como señala Levine la situación es mucho más compleja y se "olvidan" de que existen muchos creadores que reivindican su derecho a recibir una compensación justa por su trabajo creativo al que han dedicado largos años de formación y elaboración - y por lo tanto su derecho a no ser pirateados- y no por ello están coartando ningún derecho a la libre expresión política o creativa (Levine, 2013).

${ }^{5}$ En este artículo evitaremos conscientemente la cuestión de los derechos de autor y su controversia. A pesar de que se trata de un debate central en el que el discurso ciberfetichista se ha centrado, entendemos que ya se ha producido mucha literatura sobre este tema - para ver un debate acerca de la legitimidad de los derechos de autor, ver Edwards et al., 2014- y que un análisis adecuado y neutral sobre esta cuestión requeriría la atención de un artículo entero y desenfocaría el objetivo principal de este artículo, que es centrarse en el discurso ciberfetichista y el cambio en el sistema cultural. Por el contrario, nos parece más interesante, y de mayor valor, abordar la cuestión del discurso ciberfetichista sobre la comunidad y de los intermediarios desde un punto de vista sociológico.
} 


\section{La ideología californiana, el ciberfetichismo y los cambios culturales}

A menudo el ciberfetichismo se presenta como un discurso puramente factual, tecnológico o desprovisto de ideología. Sin embargo, el analizar el origen y naturaleza de este discurso proporciona herramientas para entender las razones que lo motivan como herramienta de competición en el campo de las ideas y de legitimación de los cambios sociales. ${ }^{6}$ En cuanto al origen nos referimos a un aspecto importante para entenderlo al situarlo histórica y socialmente. En el Estado español existe una gran confusión a este respecto y cuando se buscan los orígenes intelectuales de estas ideas se busca en las corrientes activistas y académicas ligadas al movimiento antiglobalización y sus raíces autonomistas y operaistas (Cf. De Nicola et al., 2008) desarrolladas y actualizadas por figuras intelectuales como Hardt y Negri (2005). No obstante, las fuentes de las que bebe el ciberfetichismo hay que situarlas en otras coordenadas espacio-temporales: en realidad su origen debemos remontarlo a la "ideología californiana", que podemos caracterizar como una combinación de actitud bohemia, utopismo tecnológico y neoliberalismo (Barbrook, 1996). Un tipo de actitud que combina bien con el estilo de vida y actitudes políticas de la generación de los burguesesbohemios (Brooks, 2001) o la neobohemia ligada a la emergencia de las industrias creativas (Lloyd, 2010). Una generación que se consolidó laboralmente y empresarialmente en los años noventa con la burbuja de las empresas punto com y desde entonces, con altos y bajos, ha ido escalando posiciones en la elite económica y social. ${ }^{7}$

${ }^{6}$ Tal y como señala Pierre Bourdieu, no pueden separarse los discursos en el campo de las ideas de la posición que ocupan en el campo intelectual u en otro campo, como el mediático o el económico, de los que lo producen. En sus palabras todo punto de vista es una vista desde un punto o posición en un campo (Bourdieu, 2002b). En este sentido cabe interpretar la toma de posición como inversiones para acumular capital simbólico y dominar el campo o bien, como planteamos en este caso, legitimar las dinámicas heterónomas y el dominio de lógicas externas dentro del campo de las idas. En este caso, nuestra tesis es que el ciberfetichismo defiende el dominio de la lógica tecnológica y económica frente a las dinámicas autónomas del propio campo cultural. No es extraño en este sentido que los que defienden las tesis ciberutopicas sobre la esfera cultural sean habitualmente personas que no participan o bien no tienen una posición relevante en los sectores culturales como profesionales o creadores. Por el contrario, se trata de individuos que desde el campo tecnológico o de la consultoría pueden tener ambiciones de mejorar su posición en el campo de la cultura en el caso de resultar vencedoras las tesis y dinámicas heterónomas ligadas a una reconversión tecnológica abrupta del sector cultural.

${ }^{7}$ Desde finales de los años dos-mil, las empresas del sector de las nuevas tecnologías han protagonizado crecimientos exponenciales hasta convertirse en una de los sectores de mayor valor bursátil en EEUU. Asimismo, estas empresas — como Google, Apple, Facebook, entre otras - han generado numerosos empleos en los segmentos altamente especializados y con altas remuneraciones. Producto de ello es que en el área de San Francisco, que atrae a una gran parte de este personal, diversas zonas urbanas se han gentrificado expulsando así a una parte de la población local de rentas bajas y a la bohemia tradicional (Corbyn, 2014). Los empleados de las grandes firmas tecnológicas, con su comportamiento neobohemio de elegir el centro de la ciudad y su rechazo de las zonas residenciales tradicionales de la clase media 
La ideología californiana representa en realidad una reconfiguración del imaginario social y una confluencia entre la nueva derecha y la nueva izquierda (Ouellet, 2009). Nacida en Silicon Valley, la meca de la llamada nueva economía, la ideología californiana se nutrió del radicalismo democrático y los movimientos contra-culturales, que promovían un ethos posmoderno (Lash, 1990). Estos movimientos insisten en la descentralización, la pluralidad y la identidad fragmentada y promueven el rechazo a las instituciones (familiares, educativas y estatales) que son consideradas impedimentos a la emancipación individual (Jameson, 1991).

Podemos considerar la ideología californiana parte de lo que Boltanski y Chiapello han caracterizado como el nuevo espíritu del capitalismo (Boltanski \& Chiapello, 2002), es decir, el nuevo discurso de legitimación de este sistema a partir de la instrumentalización por parte del management de la ideología propia de la esfera artística y de los movimientos contraculturales (Chiapello, 1998). Según esta visión, la confluencia de la ideología neoliberal y del movimiento hippy, inspirados por los textos de McLuhan (McLuhan \& Zingrone, 1997) sobre la aldea global, situarían a las nuevas tecnologías de la información primero e, internet después, como una oportunidad de crear una democracia jeffersoniana en la que los individuos podrían expresarse libremente en el ciberespacio (Ouellet, 2009). Posteriormente, desde los años noventa, esta ideología ha tomado un nuevo impulso a partir de gurús y consultores tecnológicos que han gozado de un gran éxito mediático a partir de las revistas tecnológicas como Wired o la conferencia TED, entre otros canales de difusión ${ }^{8}$. Posteriormente, este discurso ha ganado cierta profundidad intelectual y legitimidad académica con la creación de grupos de investigación en las universidades, aunque sin dejar sus posicionamientos ideológicos al considerar la tecnología — y las empresas tecnológicas - como la solución a buena parte de los problemas sociales y políticos actuales. ${ }^{9}$

A pesar de sus elementos neoliberales y antiestatales, esta ideología ha seducido a una fracción de la izquierda europea, que se ha convertido en su portavoz más activo

(Lloyd, 2010) lejos de tener un efecto beneficioso para los habitantes de las ciudades, tiene también efectos segregadores a nivel social. El sector de las nuevas tecnologías no escapa, a pesar del discurso ciberutópico, de las dinámicas "analógicas" de la estratificación social y la segregación urbana.

${ }^{8}$ A lo largo de estos últimos veinte años ha habido diferentes gurús que se han postulado como futurólogos y han pontificado sobre el impacto de la tecnología en la economía, la sociedad y la cultura. Pero sin duda uno de las figuras destacadas es Kevin Kelly, director ejecutivo de la influyente revista Wired y autor de numerosos ensayos sobre la temática (Cf. Kelly, 1998).

${ }^{9}$ Nos referimos a ciertos instituciones académicas como el Berkman Center for Internet and Society de la Univesidad de Harvard que ha desarrollado numerosas investigaciones e informes en este campo. Sin embargo, no está de más recordar que estas instituciones se encuentran financiadas (Cf. http://cyber. law.harvard.edu/about/support) por empresas tecnológicas como Google, Microsoft, Oracle, entre otras y que alguna de las propuestas de reforma legislativa o regulatoria defendidas por este centro favorecen sus intereses frente a los de la industria cultural y los creadores profesionales (Levine, 2013). 
(Rendueles, 2013). Esta situación en cierta medida paradójica se explica porque la ideología ciberutopica les ha permitido renovar el discurso con abundantes metáforas tecnológicas (red, hub, reset, etc.) y convertir a la tecnología en una especie de nuevo motor de la historia que les permitiría dejar la posición defensiva en que les había colocado la ofensiva neoliberal de los años ochenta. Sin embargo, al aceptar buena parte de los axiomas fundadores del neoliberalismo, el ciberutopismo - como otros discursos anexos como el de las clases o la ciudad creativa adoptados por la socialdemocracia de tipo liberal - en cierta medida debilitan la defensa del Estado del bienestar y sus lógicas redistributivas a favor de supuestos beneficios de la cultura y la creatividad hacia las capas excluidas de la sociedad (Mooney, 2004).

La ideología californiana, que se orgullece de hacer confluir escritores, hackers, consultores, empresarios multimillonarios y artistas ha conseguido generar una poderosa corriente de opinión pública y mediática que se ha difundido alrededor del mundo avanzado y que se ha introducido en el debate mediático y académico a partir de portavoces locales. ${ }^{10}$ En realidad por lo tanto no se trata de debates introducidos por los medios académicos sino al contrario, difundidos por los think tanks y por consultorías privadas que están ocupando un rol cada vez mayor en Estados Unidos y también en Europa a partir de su influencia en los medios de comunicación y de su condición de proveedores de discurso a los gobiernos (Schlesinger, 2008).

Así pues, el problema epistemológico de este discurso es doble: por una parte, los defensores de las posiciones ciberutópicas, a la vez que defienden unas tendencias (la primacía absoluta de lo digital sobre lo "analógico" en el mundo cultural) defienden a su vez la importancia de sus servicios para pilotar esta transición, expropiando así el discurso y la gestión sobre este proceso a expensas del propio sector cultural. ${ }^{11} \mathrm{Se}$ trata por lo tanto de un proceso que se presenta como inevitable, generando así el conocido fenómeno selfulfilling profecy (Merton, 1968). En segundo lugar, el discurso

${ }^{10}$ Unos portavoces locales que no siempre citan el origen de sus ideas, lo que en primer lugar, pondría en evidencia su falta de originalidad y, en segundo lugar, revelaría las bases materiales y los intereses empresariales que esconden unos discursos aparentemente desinteresados, una condición como señala Pierre Bourdieu para desactivar la crítica y acumular capital simbólico y ejercer la dominación dentro del campo de las ideas (Bourdieu, 2002b). Podemos ver un ejemplo de este tipo de discursos ciberutópicos que se presentan como originales y que no citan los orígenes de las ideas en el artículo-manifiesto, por poner un ejemplo reciente, "La revolución de los amateurs" (Lafuente, 2014) o bien el "Manifiesto Crowd" (Gutiérrez-Rubí y Freire, 2013).

${ }^{11}$ Se trata de un proceso similar al ocurrido con el llamado impacto social de la cultura. Este discurso, a pesar de que se basa en pocas evidencias empíricas fiables, ha triunfado como argumento legitimador del sector cultural, sustituyendo casi por completo los argumentos clásicos basados en los valores humanísticos del valor cultural, la excelencia o la innovación disciplinar. Al suceder esto, las consultorías privadas han sustituido a los propios artistas como creadores de discurso y se han hecho imprescindibles para estos y para los aparatos de gestión cultural para evaluar y por lo tanto legitimar la acción cultural (Belfiore, 2009). 
ciberutópico se asemeja en diversos aspectos al bullshit (que podemos traducir como charlatanería), analizado por Harry G. Frankfurt (2005). La charlatanería es un tipo de discurso que ni es verdad ni es mentira en términos absolutos, sino que su vaguedad y la amalgama de hechos que presenta, su carácter descriptivo y profético, lo convierten en un discurso manipulador y seductor pero difícilmente analizable y refutable empíricamente. ${ }^{12}$ Como ya ha señalado Eugeny Morozov, el discurso sobre internet y sus efectos en la sociedad parte de un defecto fundacional: la misma noción de internet se ha convertido en una imagen o metáfora tan heterogénea (en la que se incluyen infraestucturas tecnológicas, canales de comunicación, grupos empresariales, patrones de interacción social, etc.) que las afirmaciones que la incluyan no pueden ser sino aceptadas o rechazadas pero difícilmente analizadas empíricamente (Morozov, 2013).

Asimismo, el discurso ciberutópico sobre la importancia de lo digital se ha amplificado con la adopción de la noción de la industria creativa, una noción que agrupa en una misma categoría desde los sectores culturales hasta el sector tecnológico, pasando por los medios de comunicación o las artes aplicadas como la arquitectura o el diseño (O'Connor, 2007). Esta noción, que en realidad mezcla esferas de actividad con distintas lógicas sociales yeconómicas (Zarlenga et al., 2013) coloca en realidad a la esfera cultural en situación marginal en relación a las grandes industrias culturales (las grandes editoriales, las discográficas o las productoras de cine) los media y las empresas tecnológicas, muy superiores en volumen e importancia respecto a las industrias culturales. Por otra parte, la noción de industrias creativas como un todo afectado de forma igual por el cambio digital esconde que son las formas más industriales las que en gran medida están siendo afectadas plenamente por el cambio digital quedando en este sentido el sector de las artes escénicas, artes visuales o la edición de momento relativamente al margen (Levine, 2013). En este sentido, la utilización del concepto de cultura digital, usual en los medios ciberfetichistas (Cf. Lessig et al., 2005; @axebra, 2008), añade más confusión conceptual al debate al mezclar de forma intencionada el contenido con el soporte, la cultura en un sentido antropológico y la cultura como esfera especializada, el desarrollo tecnológico y la creatividad artística disciplinar. En definitiva el discurso ciberfetichista confunde la realidad y la metáfora, amalgama esferas y sectores diferenciados y mezcla análisis y prognosis, como podremos ver a continuación en la propuesta de nuevas comunidades digitales de consumo y producción cultural.

${ }^{12}$ Grignon y Passeron denunciaron este carácter de amalgama descriptiva y profética en ciertos discursos de análisis del cambio cultural y denunciaron su carácter de "concepto bulldozer", señalando metafóricamente que, donde se utilizan conceptos como "cultura de masas", no es posible un análisis riguroso desde las ciencias sociales, puesto que pueden abarcar diferentes fenómenos sociales de naturalezas distintas, como la cultura vehiculada por las industrias culturales o la cultura de las clases populares, que son elementos bien distintos (Grignon \& Passeron, 1989). 


\section{La comunidad de consumo y producción cultural en el entorno digital ¿Unos nuevos patrones de sociabilidad y creación?}

Una de las ideas-fuerza del ciberfetichista es que nos encontramos ante un nuevo tipo de sociabilidad y que, las nuevas tecnologías permitirían desarrollar nuevas solidaridades comunitarias al margen del mercado y delEstado (Shirky, 2008), que vendrían a contrarrestar la pérdida de capital social dominante en las sociedades avanzadas (Putnam, 1995). Ciertamente, la modernidad avanzada ha creado un nuevo patrón de relaciones sociales que responde a un nuevo orden económico, la sociedad postfordista (Bell, 1976). Asinismo, para algunos autores, en este contexto surgen nuevas formas de identidades postnacionales y que vendrían a debilitar las redes de solidaridad e identificación colectivas (Beck, 1992).

Esta debilitación de la estructura productiva fordista regulada por el Estado-nación, de las identidades tradicionales nacionales y sociales harían obsoletos los patrones de consumo cultural según un habitus asociado a una clase social como el que analizaba Pierre Bourdieu (1998) — y también a una trayectoria histórica nacional, como nos recuerda DiMaggio (1991) y predispondría a los consumidores hacia unos patrones de consumo más heterogéneos u omnívoros según la terminología de Richard Peterson (1992). Estas nuevas pautas, a la vez que desclasifican los consumos culturales y rompen su asociación con una clase o estatus socialdeterminado (Dimaggio, 2013), ${ }^{13}$ permiten generar nuevas identidades a partir del consumo cultural o la generación de subculturas (Hebdige, 2004). Ciertamente, diversos autores en su análisis del consumo cultural han destacado la importancia del nuevo contexto digital en la modificación de las pautas de consumo cultural y la aparición de pautas omnívoras, especialmente en las generaciones más jóvenes (Ariño Villarroya, 2010).

Como sabemos, los canales de difusión cultural y las posibilidades de reproducir sin apenas coste marginal se han incrementado exponencialmente con la transición al soporte digital de diversas expresiones culturales, especialmente el cine y la música. Sin embargo, deducir de estos hechos que asistimos a un paradigma de la abundancia cultural como se argumenta desde posiciones ciberutópicas es hacer un salto cualitativamente difícil. Ciertamente, en cuanto a la demanda de productos, podemos encontrar distribución estadística en forma de larga cola (long tail), es decir, la existencia de multitudes de pequeñas demandas que todas juntas suman un porcentaje considerable de la demanda cultural, tal y como se puede observar en el comercio electrónico (Anderson, 2008). Esta larga cola sin duda expresa la mencionada pluralización del consumo cultural y la mayor disponibilidad del repertorio de obras antiguas. No obstante, no pode-

${ }^{13}$ Por desclasificación del arte DiMaggio (1991) se refiere a la debilitación de la asociación entre un consumo cultural y una clase o estatus social (un ejemplo extremo de la clasificación del arte seria la asociación de la opera con la clase alta y el rap con la clase baja). 
mos inducir por ello que el ámbito digital diversifica los gustos culturales en relación a la creación actual ni que tampoco convierte el consumidor cultural en más crítico y activo. Al contrario, los estudios disponibles nos muestran que el consumo cultural de creaciones culturales contemporáneas se concentra cada vez más en unas pocas expresiones culturales (Elberse, 2008). Unas expresiones culturales que en una gran parte son de origen profesional (y no generadas por amateurs) o bien en expresiones culturales virales que repiten contenidos con leves variaciones (Levine, 2013; Rodríguez 2013). Además, en el caso de las plataformas digitales de comercialización o difusión de contenidos culturales son gobernadas por cada vez más complejos algoritmos que intentan deducir, a partir de los comportamientos anteriores los gustos o preferencias de los consumidores, ofreciéndoles y sugiriéndoles nuevos productos. No sabemos aún el resultado de este proceso de prescripción cultural por parte de máquinas a largo plazo, pero si partimos del principio de que tienden a recomendar productos culturales similares a los ya consumidos previamente, tendiendo por lo tanto a encerrar a los individuos en burbujas de filtros que pueden empobrecer el universo cultural de los individuos y sus horizontesintelectuales (Pariser, 2011).${ }^{14}$ Desarticulada la idea de canon cultural propio de la modernidad, los individuos pueden ver empobrecidos sus horizontes intelectuales, si no existen políticas públicas de redistribución de los bienes simbólicos.

Otro de los lugares comunes del discurso ciberutópico es que internet posibilita el surgimiento de comunidades de consumidores y productores culturales.Esta idea se apoya sobre la noción de red social y de fortaleza de los lazos sociales débiles (Granovetter, 1973), que viene facilitada por la accesibilidad de internet y la cultura de cooperación abierta que se ha generado en ella. Los ciberutópicos suelen poner como ejemplo de los buenos resultados de los lazos cooperativos el sistema operativo Linux y la Wikipedia (Gutiérrez-Rubí y Freire, 2014). Una experiencia que creen replicable en el mundo de la creación cultural, aun cuando lo primero — un sistema operativo o una enciclopedia - se trata de un universo técnico muy especializado, con unas reglas estables en sus procedimientos y bien definido respecto a las tareas a realizar por cada participante y lo segundo, la creación artística, es por definición una tarea difícil de definir en sus objetivos, de contornos y definición borrosa en cuanto a los procedimientos y división del trabajo, en permanente evolución o rupturas en cuanto a las convenciones

${ }^{14}$ Desde 2009 Google personaliza los resultados de las búsquedas según las informaciones previas guardadas sobre el usuario. Este hecho aparentemente banal, en realidad puede ser, según Pariser (2011) profundamente negativo para la concepción que hasta ahora teníamos de internet como espacio de intercambio de ideas, creaciones o gustos culturales, al modificar las información que recibimos en función del perfil que están creando de nosotros las grandes corporaciones tecnológicas. Una vez más pues, el discurso ciberutópico, bajo unas promesas de futuras arcadias de consumidores omnipotentes, nos esconde que en cierta medida nos aproximamos más, según Lanier, a un mundo parecido a una combinación del 1984 profetizado por George Orwell y al "mundo feliz” descrito por Aldous Huxley (Lanier, 2011). 
de cooperación, al implicar la creación la voluntad expresiva de un o unos individuos (Becker, 2008; Menger, 2009; Rendueles, 2013).

En cuanto a algunos autores, especialmente en los media Studies, hace años que insisten en la existencia de audiencias activas que se constituyen como comunidades de fans, re-elaboran contenidos e intentan influir en los media (Jenkins, 2009). ${ }^{15}$ Más recientemente, otros autores hacen referencia a comunidades de creadores on line que generan escenas creativas (Fuster, 2011; van Dijk, 2014). Sin embargo, utilizar la noción de comunidad en un sentido sociológico del término es problemático: autores clásicos de la sociología como Tönnies (2002) señala que las comunidades están ligadas por lazos de interdependencia y afectividad. O por otra parte Durkheim subraya que los lazos de solidaridad propios de las comunidades, la que llama solidaridad mecánica, se basan en la similitud y labaja división del trabajo social (1993). Sin embargo, las comunidades a las que hacen referencia los ciberfetichistas no cumplen las definiciones establecidas por la sociología clásica. En términos estrictos no podemos llamarlas comunidades sin devaluar de forma notoria este concepto, ya que se trata de cooperaciones puntuales basadas en capacidades técnicas especializadas y con grados de compromisos variables y eventuales (Lanier, 2011; Rendueles, 2013). Asimismo, muchas veces estos grupos cooperativos están basados en lazos profesionales previos, como los bibliotecarios y documentalistas implicados en Wikipedia o los programadores en Linux (Rendueles, op. cit.) o bien muchas veces se trata de grupos de clientes, disfrazados bajo un discurso comunitario, creado y dinamizado por las marcas comerciales para generar adhesiones a sus productos como parte de su estrategia de branding equity (Albert M. Muniz \& Thomas C. O'Guinn, 2001). Por el contrario, los mundos artísticos se basan en cadenas de cooperación relativamente estables (Becker, 2008), en círculos reducidos en los que se combina la amistad y el conocimiento mutuo con la rivalidad y la competencia (Farrell, 2001; Menger, 2009).

Por último, si por una parte el discurso ciberfetichista sobre la cultura se expresa en términos utópicos al dibujar un escenario de libertad creativa ya liberada de las constricciones impuestas por la industria cultural y las limitaciones técnicas de la era analógica, en cuanto a los sectores culturales en sí mismo, este mismo discurso se torna distópico, al anunciar el advenimiento de la fin de los intermediarios culturales, al quedar su rol obsoleto por las innovaciones técnicas que permiten la comunicación directa entre creador y consumidor. Sin embargo, estas predicciones "olvidan" que la intermediación en cultura ejerce muchos otros roles que el de transportar un paquete con libros o CDs desde el estudio del creador a la casa del consumidor como veremos a continuación.

${ }^{15}$ Esta participación puede ir desde el comentario y crítica del contenido mediático, a la elaboración de remakes o versiones hasta campañas de presión a los guionistas o a las empresas para reorientar los contenidos en un sentido determinado. Esta participación se desarrolla en ámbitos de la pop culture como las series, los cómics y últimamente los videojuegos. 


\section{4. ¿Una destrucción creativa para los intermediarios del sector cultural o un proceso de oligopolizacion creciente? Aportaciones de la sociología de la cultura}

Otro elemento en controversia es el rol de los intermediarios en el sector cultural, del que, como hemos dicho el discurso ciberutópico anuncia su desaparición en el marco de un proceso de reorganización completa del sector, asimilable a lo que Schumpeter calificaba como un proceso de "destrucción creativa" (Schumpeter, 2009). En este campo, como en otros el ciberfetichismo abraza parte de los postulados neoliberales y su doctrina del schock como motor del cambio y la modernización económica (Klein, 2012). Sin embargo, más de cuarenta años de investigación en sociología y economía del arte avalan el rol decisivo que han jugado los intermediarios culturales en diversos puntos clave de la producción y difusión artística (Moulin, 1983; Moulin, 1997; Bourdieu, 2002a).

En primer lugar, la noción de intermediario artístico es del todo inapropiada para el sector cultural, al no poderse separar claramente la fase de creación de la fase de producción o distribución, produciéndose valor o capital simbólico en todos los segmentos de la cadena de cooperación y de forma colectiva por parte de todo el campo cultural (Bourdieu, 2008). En el mismo proceso de creación intervienen diversas profesiones consideradas técnicas o de gestión pero que tienen un rol muy relevante a partir de una interacción micro en el mismo proceso y en la configuración del mismo producto final (Becker, 1984; Peterson, 1997). Asimismo, los intermediarios juegan un papel muy relevante en la creación del valor cultural, al tratarse de productos, como los obras de arte visuales, sin un valor a priori definido por el material del que están hechos o las horas de trabajo dedicadas a su elaboración y que deben ser valorizadas simbólicamente. Por otra parte, en el caso de las obras orientadas al sector más vanguardista, estas carecen de un público y una demanda previamente constituida (Bourdieu, 2002). En este caso, los intermediarios tienen la misión de apoyar el creador durante el proceso de creación del público que comprenda y aprecie las nuevas creaciones y de generación de la demanda que permita generar recursos para que el artista pueda dedicarse profesionalmente a su trabajo (Becker, 1984).

En segundo lugar, al designar intermediarios, las posiciones ciberutópicas se refieren habitualmente a la gran industriacultural, obviando que ésta se compone fundamentalmente por una miríada de micro-empresas y que en gran medida los creadores hoy en día se ven abocados a ser emprendedores de ellos mismos (Menger, 2009) para encontrar viabilidad a sus proyectos (Rowan, 2010). En tercer lugar, los intermediarios desarrollan una función esencial en el mundo artístico, que es la de gatekeeper, de interficie entre el mundo de la gestión y de la creación y de promotor de los creadores (Bourdieu, op. cit.). A partir de muchos estudios sabemos que los intermediarios, como los marchantes de arte ejercen un rol fundamental en los inicios y desarrollos de las 
carreras artísticas sin que ello pueda ser reducido a un simple agente de ventas (Moulin, 1983; Moulin, 1997). En el sector de la música los productores desarrollan un rol decisivo entre el sector de la música, la industria y los públicos, favoreciendo la innovación en un contexto inestable (Rubio \& Rius, 2014). Desde posiciones ciberutópicas se ha acusado a estos intermediarios de generar escasez artificial frente a la creatividad actual favorecida por las nuevas tecnologías. Sin embargo, estas afirmaciones obvian que no son sólo los intermediarios los que generan distribuciones desiguales de éxito o reconocimiento, sino que los mismos patrones de consumo cultural de la ciudadanía son los que generan distribuciones próximas al esquema de repartición de ganancias winner takes all, es decir, a una concentración de los ingresos en unos pocosindividuos (Menger, 1999). Una tendencia que el mayor desarrollo de la sociedad de consumo y de los mass media, incluido internet, no parece haber disminuido sino agravado y concentrado además en aquellos segmentos del mundo cultural más ligado a los artistas-mediáticos y las celebrities (Currid-Halkett \& Scott, 2013; Crane, 2009). No es por lo tanto que los intermediarios generen escasez sino que a contrario son los únicos que pueden asegurar que aquellos creadores que no han recibido la atención del gran público y los media puedan continuar creando a partir de mecanismos de reinversión de las ganancias extraídas de los autores y proyectos exitosos. ${ }^{16}$ Por lo tanto, después del debilitamiento de los intermediarios - y su función de selección y valorizacióny la aparición de las nuevas tecnologías de comercialización cultural podemos estar observando no una mayor diversidad en la producción cultural, sino precisamente una reducción de los autores y creadores que realmente acceden a una posición de visibilidad social y/o de mercado. ${ }^{17}$

${ }^{16}$ Diversos estudios en diferentes sectores de las industrias culturales confirman que la mayor parte de los proyectos culturales son fallidos y que solamente una pequeña parte de los proyectos que son un éxito en términos de público y resultados económicos. Estos pocos permiten financiar al resto de los proyectos, asegurar la viabilidad de las empresas culturales y, por lo tanto, mantener una diversidad de autores y artistas a pesar de que no todos hayan conseguido el éxito en todos sus proyectos, Cf. Bourdieu (2002) por el sector editorial, Moulin (1992) por el sector de las artes visuales o Peterson (1971) por el sector de la música). Al ser la actividad creativa una profesión con un riesgo inherentemente alto, los intermediaros socializan el riesgo (Menger, 2009), por lo tanto, si desaparece estos agentes, el riesgo puede quedar totalmente en manos del creador, que verá así un poco más precarizada su situación laboral (Bureau et al., 2009).

${ }^{17}$ Otro de los grandes mitos del discurso ciberutopista es que el aumento de la posibilidad técnica de producir productos culturales de calidad similar o igual a los productos culturales profesionales y la debilitación de los intermediarios (galeristas, editores, agentes musicales y cinematográficos, etc.) abrirá la posibilidad de una democratización de la cultura. Sin embargo, después de más de una década de la popularización del internet a alta velocidad y del P2P, son escasos los ejemplos de autores y creadores que han conseguido fama o ingresos suficientes para vivir de los ingresos por su obra, al margen del sistema establecido por los intermediarios. Por ejemplo, el sistema de la auto-edición que tantas expectativas ha generado muestra escasa capacidad de promover a los autores: solamente un $35 \%$ se consideran escritores profesionales y un escaso $20 \%$ se muestran satisfechos con el impacto mediático y las ventas del libro (Cf. Geli 2013). 
Como hemos analizado antes, el paradigma ciberutópico parte de la idea de que se ha pasado de un estado de escasez a un estado de abundancia de producciones culturales a los que los consumidores tienen acceso, con la tesis de que los intermediarios han dejado de ejercer un rol de facilitador del acceso a constituir un "obstáculo" al libre acceso, reproduciendo así el discurso de posiciones próximas a la industria tecnológica como las difundidas por Kelly (1998) y reproducidas en España de forma imitativa por parte de consultores y académicos locales (Celaya et al., 2013 y van Dijck, 2013). Este paradigma ciberutópico se fundamenta en dibujar un futuro prometedor y de cambio social democratizador a partir de los cambios tecnológicos, y de ahí su carácter seductor como señala Rendueles (2013). Sin embargo, ello nos esconde que esta supuesta democratización se produce no por el reconocimiento y valorización de las culturas populares o minoritarias o bien a partir de una mejora real del acceso a la cultura, sino a partir del acceso teórico a partir de la popularización de los diversos gadgets tecnológicos que en principio lo harían posible como ordenadores personales o portátiles, tablets, smartphones, etc. No obstante, no se analiza a fondo si este fenómeno realmente es lo que está sucediendo en la dinámica de consumo y apropiación cultural, si continúan existiendo significativos gaps o desigualdades como algunos estudios sugieren (Schradie, 2011) o, si existen efectos no deseados de este "solucionismo tecnológico" como un menor respeto a la libertad, la privacidad y la autonomía individual (Morozov, 2013). Además, estas perspectivas esconden que, con el debilitamiento de los intermediarios y su capacidad de prescripción, el poder de elección no bascula hacia el consumidor. Sino que con ello, el control lo obtienen en buena medida las grandes compañías tecnológicas que con sus procedimientos de análisis del big data (es decir, los datos masivos de los consumidores recogidos y explotados de forma sistemática) convierten al consumidor y sus elecciones en la fuente de ingresos y posición dominante en el mercado cultural (Colombani y Videlaine, 2013). ${ }^{18}$

Frente a estos estudios ampliamente reconocidos y contrastados de las ciencias sociales, se afirma desde las posiciones ciberutópicas (a partir de su asimilación al sector tecnológico y educativo, y a partir de estudios de consultorías o think tanks relacionados con las industrias tecnológicas) que los intermediarios han dejado de aportar valor añadido a la cadena de produccióncultural (Kelly, 1998). Estas visiones son apoyadas de forma ferviente por algunos activistas y académicos ciberfetichistas, algunos

${ }^{18}$ Big data se ha convertido en otro de los conceptos fetiche del discurso ciberfetichista, que diversos consultores se han apresurado a querer aplicar al mundo cultural como una forma de mejorar la gestión de las empresas (L'Atelier, 2013) hasta medir de forma más completa el valor cultural de las organizaciones (Lilley y Moore, 2013). Sin embargo, estas visiones claramente sobre-evalúan el potencial de los datos masivos para evaluar procesos complejos y multidimensionales como es la gestión cultural. Además, debemos ser conscientes de la debilidad de estos procesos que muestran correlaciones entre variables que no han sido creadas para la investigación y con un marco teórico de referencia. El resultado por lo tanto de buena parte de estos procesos es mostrar asociaciones de muy limitado valor interpretativo. 
financiados por las compañías tecnológicas a las que beneficia esta transformación (Google, Amazon, Apple, entre otras). ${ }^{19}$ Por ello, en países como Francia, ha surgido una corriente de opinión entre los expertos en política cultural que juzga la desaparición de los intermediarios, en particular en el sector del libro, como un primer paso hacia una monopolización de la difusión cultural, un empobrecimiento de la esfera cultural, una reducción de la diversidad cultural y una amenaza a la soberanía política y económica nacional (Kert, 2013). ${ }^{20}$

Para terminar, examinaremos una de las iniciativas destacada por el ciberutopismo que según esta visión combinaría participación ciudadana con cooperación creativa, en una forma que debería reemplazar el actual sistema de financiación de la cultura mixto público-privado.

\section{5. ¿EI Crowdsourcing: pilar de un nuevo sistema cultural?}

Frente a la caída de ingresos de la industria cultural y los creadores por la piratería, que el discurso ciberfetichista juzga como inevitable y hasta positivo (Kelly, 1998), sus partidarios han propuesto diversas alternativas para generar ingresos como la realización de conciertos, las plataformas de difusión de música (Spotify y similares) ${ }^{21}$, unas propuestas que se han revelado más prometedoras que factibles para permitir la supervivencia de la escena musical. Sin embargo, unas de las propuestas estrella sin duda se ha convertido en el crowdsourcing de los proyectos culturales, como el sistema de financiación y gestión de proyectos alternativo al mercado capitalista y al Estado y su burocracia.

El crowdsourcing, traducido al castellano de forma un tanto confusa como micromecenazgo, es propuesto insistentemente como una alternativa al colapso de las estruc-

${ }^{19}$ En este sentido cabe denunciar como hace Robert Levine las conexiones entre ciertos activistas y académicos y las grandes compañías tecnológicas y sus lobbies o fundaciones que promueven y financian estudios sobre cambios en la política cultural y sus regulaciones a fin de afianzar su dominio en la esfera de la distribución de contenidos así como la modificación de las legislaciones a su favor para no impedir estos procesos de monopolización (Levine, 2013).

${ }^{20}$ En este sentido, como reacción a este fenómeno de monopolización, hay que destacar la aprobación en Francia de la Proposición de Ley para que los gastos de entrega a domicilio no puedan ser incluidos en el precio (único) del libro, con el objetivo de que las librerías puedan competir con la empresa Amazon.

${ }^{21}$ Todas estas propuestas se han revelado del todo insuficientes para generar ingresos para la industria cultural y los creadores. En cuanto a los ingresos por conciertos, estos en España se han reducido casi a la mitad desde el inicio de la crisis y se concentran progresivamente en un reducido número de estrellas del pop rock (Rubio et al., 2014). En cuanto a las plataformas como Spotify han recibido numerosas críticas por parte de los creadores por su opacidad en los criterios de asignación de remuneraciones y por la ridícula cantidad que ofrecen a los artistas (Cf. Rolling Stone, 2013). 
turas de financiación y desarrollo de los productos culturales (Gutiérrez-Rubí y Freire, 2013) y es presentado como una forma superior de organización al mercado y al Estado para la asignación de recursos al aprovechar la "sabiduría de las multitudes", es decir, la agregación de pequeñas pero múltiples decisiones individuales (Surowiecki, 2004). Sin embargo, otra vez nos encontramos con un discurso ciberutópico que mezcla el nivel descriptivo con el normativo sin aportar más datos que las proyecciones realizadas por los propios agentes interesados (Massolution, 2013) o planteándose como la única alternativa posible a una deseable retirada del Estado (Gutiérrez-Rubí y Freire, 2013). ${ }^{22}$ Así pues, el crowdfunding se constituye, según esta visión, como una alternativa a la financiación privada o pública, que dota a los creadores de una nueva autonomía frente a los ejecutivos de las industrias culturales y a los burócratas del Estado y como un fenómeno emergente pero que goza de gran eco mediático y cuenta con grandes expectativas de crecimiento a corto y medio plazo en paralelo a al crecimiento de medios de comunicación sociales y la economía digital (ibídem).

Pero, más allá de las promesas, ¿cuál es la realidad actual del crowdfunding? En primer lugar, debemos distinguir entre varios tipos de crowdfunding: préstamos peerto-peer, inversiones con un rendimiento compartido, pre-ventas o recompensas y donaciones puras. La mayoría de estudios coinciden en señalar que predominan las pre-ventas y las donaciones puras, representando entre las dos entre el $50 \%$ y el $75 \%$ de la cifra total según lasfuentes (Saublens, 2013). En cuanto a las dimensiones cuantitativas existen pocos estudios, por lo que debemos fiarnos de diversas estimaciones: se calcula por ejemplo que existen a nivel mundial 1 millón de proyectos en 600 plataformas de crowdfunding que en total gestionan unos 920 millones de dólares (Massolution, 2013). No tenemos datos fiables para España, así que si analizamos el caso de un país cercano, Francia, podemos ver que entre 2008 y 2011 se han creado 25 plataformas que han financiado 15.000 proyectos por un montante global de 6 millones de euros gracias a 35.000 inversores. ${ }^{23}$ Finalmente, según estimaciones de crowdfunding.org, en España, solamente existen 13 plataformas y, según un reciente estudio sobre la plataforma Verkami, en sus dos primeros años ha gestionado 242 proyectos con un total global de facturación de un millón deeuros (Bonet, 2013). Sin embargo, hay que tener en cuenta que solamente un 20\% aproximadamente de los proyectos sonculturales (Massolution, 2013). Así pues, teniendo en cuenta por lo tanto que el gasto público en cultura el 2011 era de casi seis mil millones de euros, podemos deducir que la aportación del crowdfun-

${ }^{22}$ Sin embargo, una mirada más neutral y menos ciberfetichista, puede recordarnos que la financiación colectiva de proyectos de interés público no es ni mucho menos nueva y que buena parte de las instituciones culturales y sociales emergidas a finales del siglo XIX y principios del siglo XX, los llamados ateneos, fueron financiados por "suscripción popular" (Roselló \& Rius 2009). La pregunta por lo tanto es: ¿el mecanismo tecnológico modifica la lógica social del mecenazgo popular o bien se basa en lógicas precedentes, aunque sean presentadas como nuevas?

${ }^{23}$ La Tribune, 27/03/2012, Meeting 26.03.12 en el Palais Brongniart. 
ding al sistema cultural es, por decirlo de algún modo, muy pequeño y su posibilidad de compensar la pérdida de financiación pública seria irrisorio (Rubio et al., 2014). ${ }^{24}$

Por otra parte, en términos cualitativos, las plataformas de crowdfunding plantean diversas dudas o retos. En primer lugar, existe un riesgo no neglibible de que el proyecto no financiado no se lleve a cabo, riesgo ante el que los financiadores no están protegidos. Tampoco es muy claro el nivel de implicación y conocimiento que pueden/ deben disponer del proyecto los financiadores y su derecho/capacidad de influenciar al creador (Eurada, 2012). En segundo lugar, la gran mayoría de proyectos culturales financiados son proyectos que pueden ofrecer un producto final reproducible digitalmente o bien que tienen un soporte material con el que "compensar" al financiador (música o cine, con grabaciones o films respectivamente). Queda por lo tanto la incógnita de si el crowdfunding de tipo cultural ganará amplitud y permitirá incluir con semejante peso que los sectores anteriores el resto de artes, especialmente aquellas que suelen tener una existencia efímera o un producto único (artes escénicas y visuales). En tercer lugar, este tipo de mecanismos pueden ser muy útiles para la financiación de proyectos culturales en sus fases iniciales. Sin embargo, tampoco es evidente que proceso deben seguir estos proyectos cuando ganen dimensión o cuando necesiten canales más masivos de difusión. En cuarto lugar, los proyectos de crowdfunding son dirigidos a financiar una actividad pero no están pensados para generar unos ingresos regulares y durables a los artistas o gestores, contribuyendo así a la creciente precarización del trabajo creativo (Menger, 2009; Bureau et al., 2009). En quinto lugar, debe considerarse asimismo que se trata de un fenómeno que expresa lógicas sociales y culturales distintas: utilizando la terminología de Polanyi (2006) en el crowdfunding la lógica del don, el de la reciprocidad, del intercambio en el mercado que pueden entrar en contradicción, generando tensiones en el mismo proyecto al responder a diferentes objetivos. En sexto lugar, desde el punto de vista de la gestión pública, es una herramienta muy potente para implicar a nuevos sectores en la gestación de nuevos proyectos de creación, difusión y/o participación. Sin embargo plantea numerosos interrogantes éticos y políticos si las administraciones públicas pueden utilizar este mecanismo de recaudar financiación para protección del patrimonio, financiación de grandes organizaciones o la prestación de servicios básicos, unos objetivos que consumen gran parte de los presupuestos públicos. ${ }^{25}$ Finalmente, desde el punto de vista de la gestión pública, mecanismos como

${ }^{24}$ Se estima que la disminución de los recursos públicos en España entre 2009 al 2013 ha sido del 45\% (Rubio et al., 2014).

${ }^{25}$ En este sentido es interesante la reflexión que haceMartí Casas (2013) en relación a la campaña del Ayuntamiento de Barcelona, al recaudar mediante crowdfounding fondos para rehabilitar los murales del Monasterio de Pedralbes de la capital catalana. Martí (op. cit.) destaca la problematicidad de que una administración pública saneada como el gobierno local de la capital catalana capte fondos para un objetivo de protección patrimonial al que está obligado y que podrían ser dedicados a otros objetivos de carácter socio-cultural o a entidades con menor capacidad económica. Asimismo señala la contradicción de usar 
el crowdfunding representan un gran aporte a proyectos con un potencial de generar resultados, capacidad de seducción o visibilidad social y, por lo tanto, capaces de recompensar material o simbólicamente al ciudadano-financiador. Ello puede generar más recursos para las iniciativas o entes con capacidad de gestión y promoción pero puede dejar igual o hasta marginar iniciativas con menor efecto a corto plazo, menos vistosas o con menor potencial de distinción. En este sentido, el crowdfunding puede ser considerado un mecanismo que, lejos de tener un efecto redistributivo, puede acabar generando mayor desigualdad entre proyectos culturales de forma similar al mecenazgo tradicional (Arts \& Business, 2012).

Por lo tanto, un análisis ponderado y holístico del crowdfunding resitúa su dimensión y deja numerosos interrogantes abiertos. En primer lugar, actualmente y con los datos disponibles el crowdfunding dista mucho de ser a nivel internacional, nacional o local una estructura suficientemente potente como para sustituir o ni tan sólo complementar a la actuación del Estado en el ámbito cultural. En realidad, la aportación conjunta no bastaría ni para pagar el capítulo I de personal de una institución cultural de talla mediana. Tampoco parece que pueda sustituir al mecanismo de mercado para establecer relaciones de cooperación estables entre profesionales en los diferentes estadios de carrera artística. Por lo tanto, estamos muy lejos de poder ver un proceso de cambio del sistema institucional del mundo cultural como el ocurrido en la segunda mitad del siglo XIX del sistema académico al de mercado (White, 1993). Y si en todo caso representará un nuevo sistema en la participación y la financiación de la cultura, diversos aspectos deberían corregirse para dotarlo de coherencia, estabilidad y fiabilidad al mecanismo. Finalmente, sus finalidades democratizadores se limitarían más a ampliar el número de personas implicadas en la financiación cultural, pero no parece favorecer la pluralidad y variedad de las expresiones culturales y tampoco parece contribuir a la democratización del acceso a la cultura.

\section{Conclusiones}

Desde hace unos años el debate sobre el futuro del sector cultural ha ganado centralidad social y se ha visto inmerso en un debate de marcado carácter político e ideológico. Ello expresa, sin duda, fenómenos de fondo de la reestructuración del sistema capitalista y de la nueva importancia de los factores simbólicos en la configuración de un nuevo orden económico y social (Boltanski \& Chiapello, 2002) y del nuevo rol en este contexto otorgado al consumo y la producción cultural (Scott, 2007). En el contexto de la emergencia de las transformaciones digitales ha surgido un discurso que hemos calificado

los canales digitales y al mismo tiempo, una costosa publicidad en prensa y cartelería en la calle, usada precisamente para publicitar la campaña de crowdfunding. 
de ciberutópico, que hunde sus raíces en la convergencia de postulados neoliberales y libertarios de la neobohemia y que defiende que las transformaciones tecnológicas aportadas por las nuevas tecnologías de la información conducirán a una transformación económica y social de gran profundidad.

Sin negar las múltiples transformaciones que estas imponen, es urgente y necesario realizar una ruptura epistemológica con este discurso para poder analizar las consecuencias reales de éstas, sin la contaminación ideológica que comporta el discurso ciberutópico. A partir de las aportaciones de la sociología de las artes y la cultura, podemos constatar que gran parte de los postulados de los que parte el discurso ciberutópico se revelan en gran medida erróneos o bien deben ser muy matizados. En primer lugar, las nuevas tecnologías no conducen a una diversificación del consumo cultural ni al empoderamiento del consumidor, sino que al contrario, pueden concentrar el interés hacia lo que las grandes empresas tecnológicas y sus procedimientos de selección y prescripción. En segundo lugar, las transformaciones tecnológicas debilitan la intermediación cultural y con ello los procesos de creación de valor cultural, especialmente en aquellas expresiones más complejas, innovadoras y arriesgadas culturalmente. Asimismo, la acumulación de datos y de volumen por parte de las grandes empresas tecnológicas, conduce a posiciones de dominio oligopólico que a medio y corto plazo pueden conducir no solamente a una situación de empobrecimientos de la diversidad cultural sino a una debilitación del sistema cultural en su conjunto y a un control y vigilancia efectiva de los contenidos creados. Finalmente, hemos visto cómo uno de los mecanismos propuestos para el cambio de sistema cultural se revela aún muy frágil, parcial e incapaz de remplazar el sistema mixto de mercado regulado y subvencionado que se construyó paralelamente a la regulación de la economía y a la construcción de la política social de la posguerra.

Es probable que algunos de los lectores compartan con el discurso ciberfetichista algunas de las críticas del rol ejercido por parte de la industria cultural o por las sociedades de gestión de los derechos de autor, que sin duda requieren un proceso de refundación y democratización (Edwards et al., 2014). O bien que compartan la necesidad de ofrecer un paradigma abierto y accesible para el conocimiento generado desde instituciones educativas públicas a fin de modernizar y democratizar el conocimiento (Ariño, 2009). Y también podemos participar de la idea de que sería conveniente revisar el rol que puede ejercer el tercer sector cultural como un ámbito que, con una adecuada autonomía de gestión, pueda desarrollar proyectos participativos a nivel social que constituyan un bien común (Subirats et al., 2011). Se trata sin duda de ideas que compartimos y que hemos analizado y considerado positivas en otras ocasiones (Rubio et al., 2014). Es probable también que nunca volvamos atrás al periodo de la modernidad cultural, en el que la esfera artística gozaba de una notable autonomía y establecía tendencias que posteriormente seguirían otras esferas sociales. 
Sin embargo, el discurso ciberutópico al que nos hemos referido se revela no solamente un discurso poco útil para el desarrollo del mundo cultural y de la accesibilidad y participación cultural al presentarnos como inevitables procesos de reestructuración económica abiertos y gobernables y ofrecernos tablas de salvación que se aseveran inviables o contraproducentes. Al contrario, el discurso ciberfetichista se revela en realidad como un obstáculo al análisis crítico de algunas de las tendencias y amenazas a las que se enfrenta la esfera cultural. Unas amenazas bien reales, como el mayor control oligopólico del mercado y de una vulneración de la privacidad por parte de las grandes empresas tecnológicas, unas empresas que paradójicamente habían gozado hasta hace bien poco, gracias al discurso ciberutópico, de una imagen idílica como democratizadoras de la cultura. ${ }^{26}$ En definitiva, podemos entender la fascinación que ha ejercido este discurso al relacionar nuevas tecnologías con la promesa de una democracia cultural sin burocracia estatal ni industrias culturales. Con todo, más que aportar claridad y capacidad de transformación, el discurso ciberutópico dificulta abordar con rigurosidad y realismo no solamente las ventajas sino también los riesgos —o los efectos no deseados - que puede suponer la transición a lo digital para la cultura y las artes en la era digital.

\section{Bibliografía}

@aXeBra, (2008): Cultura libre digital, Barcelona, Icaria Editorial.

Albert M. Muniz, J. \& Thomas C. O’Guinn, (2001): "Brand Community”, Journal of Consumer Research, 27(4), pp.412-432.

Anderson, C. (2008): The Long Tail: Why the Future of Business Is Selling Less of More, Hyperion.

Ariño Villarroya, A. (2010): Prácticas culturales en España: desde los años sesenta hasta la actualidad, Barcelona, Ariel.

Ariño Villarroya, A. (2009): El Movimiento Open: la creación de un dominio público en la era digital, València, Universitat de València.

Ariño Villarroya, A. (1997): Sociología de la cultura. La constitución simbólica de la sociedad, Barcelona, Ariel

ARTS \& Business (2012): Where is Private Investment to the Arts going in England?, London, Arts \& Business.

${ }^{26}$ El apoyo incondicional que desde posiciones ciberfetichistas han mostrado hacia las grandes empresas tecnológicas, especialmente Google, empieza a perder legitimidad con su crecimiento exponencial como empresa, su capacidad para no pagar impuestos a partir de ingeniería financiera o bien su colaboración con el espionaje masivo por parte de los servicios de inteligencia estadounidenses como ha revelado Edward Snowden (Quintana, 2014). 
Barbrook, R. \& A. Cameroon (1996): "The Californian Ideology", Science as Culture, 26(1), pp. 44-72.

BECK, U. (1992): Risk society : towards a new modernity, London, Sage.

Becker, H.S. (2008): Los mundos del arte. Sociología del trabajo artístico, Buenos Aires, Universidad Nacional de Quilmes.

Belfiore, E. (2009): "On bullshit in cultural policy practice and research: notes from the British case”, International Journal of Cultural Policy, 15(3), pp.343-359.

BeLl, D. (2007): Las contradicciones culturales de la modernidad, Barcelona, Anthropos.

Bell, D. (1976): The Coming of Post-Industrial Society: A Venture in Social Forecasting, Basic Books.

Boltanski, L. y E. Chiapello (2002): El nuevo espíritu del capitalismo, Madrid, Akal.

Bonet, L. (2013): "Diagnosi de la cultura a Barcelona 2012: la crisi del finançament”, Barcelona Cultura, Balanç 201(8), p.33.

Bourdieu, P. (1998): La distinción. Criterios y bases sociales del gusto, Madrid, Taurus.

Bourdieu, P. (1977): "La production de la croyance : contribution à une économie des biens symboliques", Actes de la recherche en sciences sociales, 13, pp.3-43.

Bourdieu, P. (2002a): Las Reglas del arte: génesis y estructura del campo literario, Barcelona, Anagrama.

Bourdieu, P. (2002b): Razones prácticas: sobre la teoría de la acción, Barcelona, Anagrama.

Bourdieu, P. (2008): “Pero, ¿Quién creo a los creadores?”, en Cuestiones de sociología, Madrid, Akal.

Bourdieu, P., J.C. Chamboredon y J. C. Passeron (1994): El Oficio de sociólogo: presupuestos epistemológicos, Madrid, Siglo XXI.

Brooks, D. (2001): Bobos In Paradise: The New Upper Class and How They Got There, New York, Simon \& Schuster.

Bureau, M.-C., Perrenoud, M. \& Shapiro, R. (2009): L'artiste pluriel. Démultiplier l'activité pour vivre de son art, Villeneuve d'Ascq, PU du Septentrion.

Casas, M. (2013): "Encerts i desencisos del micromecenatge de Pedralbes", Barcelona, Blog personal Embaladits (Acceso: 28/02/2014).

Celaya, J., P. Rausell y A. Villarroya (2013): La internacionalización de las industrias culturales y creativas españolas, Madrid, Fundación Alternativas / Google.

ChiAPEllo, E. (1998): Artistes versus managers: le management culturel face à la critique artiste, Paris, Métailié, Diffusion, Seuil.

Colombani, Laurent; y F. Videlaine (2013): Les nouvelles prescriptions: de l'abondance à la Découverte. Rapport Bain \& Company 2013 sur la consommation numérique des biens et services culturels pour le Forum d'Avignon. Paris, Bain \& Company. 
Crane, D. (2009): "Reflections on the global art market: implications for the Sociology of Culture”, Sociedade e Estado, 24(2), pp.331-362.

Corbyn, Z. (2014): "Is San Francisco losing its soul? The big pay cheques of the tech boom are changing the City by the Bay as Twitter and Google millionaires take over its bohemian haunts. Could this be the end of the city as we know it?", The Guardian, 23-2-2014.

Currid-Halkett, E. \& A.J. Scott. (2013): "The geography of celebrity and glamour: Reflections on economy, culture, and desire in the city", City, Culture and Society, 1: 1, pp.1-19.

De Nicola, A., B. Vecchi y G. Roggero (2008): "Contra la clase creativa", en Producción cultural y prácticas instituyentes, Madrid, Traficantes de Sueños, pp. 43-58.

Dimaggio, P. (2013): “Classification in Art”, American Sociological Review, 52(4), pp.440-455.

DiMaggio, P. (1991): "Social Structure, Institutions and Cultural Goods: The Case of the United States", en P. Bourdieu \& J. Coleman, eds., Social Theory for a Changing Society, Boulder, Westview Press, pp. 133-166.

Durkheim, É. (1993): La división del trabajo social, Barcelona, Planeta-Agostini.

Edwards, L., B. Klein \& D. LeE (2014): "Discourse, justification and critique: towards a legitimate digital copyright regime?", International Journal of Cultural Policy, DOI: $10.1080 / 10286632.2013 .874421$

Elberse, A. (2008): "Should You Invest in the Long Tail?", Harvard Business Review, Harvard Business Review, 2(1), pp.45-53.

Eurada. (2012): Crowdfunding Meeting. Meeting Hosted by the European Economic and Social Committee. 7 June 2012. Scoping Paper.Bruselas: Eurada.

Farrell, M.P. (2001): Collaborative Circles: Friendship Dynamics and Creative Work, Chicago, University of Chicago Press.

Frankfurt, H.G. (2005): On Bullshit, New Jersey, Princeton University Press.

Fuster Morell, Mayo (2011): Acción colectiva a través de redes online: Comunidades de Creación Online para la construcción de bienes públicos digitales. Redes. 6, pp. 229247.

Geli, C. (2013): "La autoedición explota en Fráncfort", El País, 12-10-2013.

Granovetter, M.S. (1973): 2The Strength of Weak Ties", The American Journal of Sociology, 78(6), pp.1360-1380.

Grignon, C. y J.C. PASSERON (1989): Le savant et le populaire: misérabilisme et populisme en sociologie et en littérature, Paris, Gallimard : Seuil.

GutiérRez-Rubi, A. y J. Freire (2013): Manifiesto Crowd. La empresa y la inteligencia de las multitudes. Madrid, Laboratorio de tendencias. 
Hardt, M. y A. Negri (2000): Imperio, Barcelona, Paidós.

Hebdige, D. (2004): Subcultura: el significado del estilo, Barcelona, Paidós.

JAMESOn, F. (1991): Postmodernism, or the Cultural Logic of Late Capitalism, London, Verso.

JAMESON, F. (1996): Teoría de la postmodernidad, Madrid, Trotta.

Jenkins, H. y P. Hermida Lazcano (2009): Fans, blogueros y videojuegos : la cultura de la colaboración, Barcelona etc., Paidós.

KeLLY, K. (1998): New rules for the new economy: 10 ways the network economy is changing everything, London, Fourth Estate.

Kert, Christian. (2013): "Rapport au nom de la Comission des Affaires Culturelles et de l'Éducation sur la Propositiond de Loi tendant à ne pas intégrer la prestation de la livraison à domicile dans le Prix Unique du Livre.” Assemblée Nationale Quatorzième Législature (1385), pp. 1-39.

KLEIN, N. (2012): La doctrina del shock: el auge del capitalismo del desastre, Barcelona, Paidós.

LAfuente, G. (2014): La revolución de los amateurs, El Diario, 28/03/2014.

LANIER, J. (2011): Contra el rebaño digital: Un manifiesto, Barcelona, Random House Mondadori.

LANier, J. (2013): Who owns the future?, New York, Simon \& Schuster.

LASH, S. (1990): Sociology of Postmodernism, London, Routledge.

Lessig, L., Córdoba, A. y J. CAndeira (2005): Por una cultura libre: cómo los grandes grupos de comunicación utilizan la tecnología y la ley para clausurar la cultura y controlar la creatividad, Madrid, Traficantes de Sueños.

Levine, R. (2013): Parásitos: cómo los oportunistas digitales están destruyendo el negocio de la cultura, Barcelona, Ariel.

Lilley, A. \& P. Moore (2013): Counting what counts. What big data can don for do for the cultural sector, London, Magic Lantern.

L'Atelier (2013): Big data: the growing power of the data and its oulook for the economy of culture, L'Ateleier. Paris, BNP Paribas Group - Forum Avignon.

Lloyd, R. (2010): Neo-Bohemia: Art and commerce in the postindustrial city, Nueva York, Routledge.

Massolution (2013): Crowdfunding Industry Report, Los Angeles, Massolution.

McLuhan, E. \& F. Zingrone (1997): Essential McLuhan, London, Routledge.

Menger, P.-M. (1999): “Artistic Labor Markets and Careers”, Annual Review of Sociology, 25, pp.541-574.

Menger, P.M. (2009): Le travail créateur. S'accomplir dans l'incertain, Paris, Gallimard.

Merton, R.K. (1968): Social theory and social structure, London, Collier MacMillan. 
Mooney, G. (2004): "Cultural Policy as Urban Transformation? Critical Reflections on Glasgow, European City of Culture 1990”, Local Economy, 19(4), pp.327-340.

Morozov, E. (2012): El Desengaño de internet: los mitos de la libertad en la red, Barcelona, Destino.

Morozov, E. (2013): To save everything, click here : technology, solutionism, and the urge to fix problems that don't exist, London, Allen Lane.

Moulin, R. (1997): L'Artiste, l'institution et le marché, Paris,Flammarion.

Moulin, R. (1983): Le marché de l'art en France, Paris, Éditions de Minuit.

O'ConNor, J. (2007): The cultural and creative industries: a review of the literature, London, Creative Partnerships - Arts Council England.

Ouellet, M. (2009): "Cybernetic Capitalism and The Global Information Society : From the Global Panopticon to a "Brand" New World", en M. Best \& J. Paterson, eds., Cultural Political Economy, London, Taylor \& Francis, pp. 177-205.

Pariser, E. (2011): The Filter Bubble: What The Internet Is Hiding From You, New York, The Penguin Press.

Peterson, R.A. (1992): "Understanding Audience Segmentation: From Elite and Mass to Omnivore and Univore", Poetics, 21-4, pp.243-258.

Peterson, R.A. (1971): "Entreprenurship in Organizations: Evidence from de Popular Music Industry", Administrative Science Quarterly. 16:1, pp. 97-106.

Polanyi, K. y J.E. Stiglitz (2006): La Gran transformación: los orígenes políticos y económicos de nuestro tiempo, México, Fondo de Cultura Económica.

Putnam, R.D. (1995): "Bowling Alone: America's Declining Social Capital”, Journal of Democracy, pp.65-78.

QuintanA, Y. (2014): "Cuáles son y cómo funcionan los programas de espionaje de la NSA", El Diario, 19/03/2014.

ReNDueles, C. (2013): Sociofobia : el cambio político en la era de la utopía digital, Madrid, Capitán Swing.

RodRíGuez, D. (2013): Memecracia: Los virales que nos gobiernan, Barcelona, Grupo Planeta.

Rolling Stone (2013): "Los músicos contra Spotify: la lucha continúa”, Rolling Stone, 23/07/2013.

Rubio Arostegui, A., J. Rius y S. Martinez Illa (2014): El modelo español de financiación de las artes y la cultura en el contexto europeo, Madrid, Fundación Alternativas.

Saublens, C. (2013): "Grouth of Crowdfunding. Drivers and Obstacles", Bruselas, Conference Crowdfunding: Untapping its potential, reducing the risks.

Schlesinger, P. (2008): "Creativity and the Experts: New Labour, Think Tanks, and the Policy Process", The International Journal of Press/Politics, 14(1), pp.3-20. 
Schradie, J. (2011): "The digital production gap: The digital divide and Web 2.0 collide", Poetics, 39, pp. 145-168.

Schumpeter, J.A. (2009): Can Capitalism Survive?: Creative Destruction and the Future of the Global Economy, New York, Harper.

ScotT, A. (2007): Capitalism and Urbanization in a New Key? The Cognitive-Cultural Dimension. Social Forces, 85(4), pp.1465-1482.

SHIRKY, C. (2008): Here Comes Everybody. The Power of Organizing Without Organizations, New York, The Penguin Press.

Subirats, J., X. Fina, N. Barbieri y E. Merino(2011): Proximitat, cultura i tercer sector a Barcelona, Barcelona, Icaria.

Surowiecki, J. (2004): The Wisdom of Crowds: Why the Many Are Smarter Than the Few and How Collective Wisdom Shapes Business, Economies, Societies and Nations Details: James Surowiecki, New York, Doubleday.

Tönnies, F. (2002): Community and Society, New York, Courier Dover Publications.

van DiJK, Y. (2014): “Amateursonline: Creativity in a community", Poetics, http://dx.doi. org/10.1016/j.poetic.2014.02.001

White, H.C. (1993): Careers and creativity: social forces in the arts, Colorado, Westview Press.

Zarlenga, M.I., J. Rius Ulldemolins y A. Rodríguez Morato (2013): · Cultural clusters and social interaction dynamics: The case of Barcelona”, European Urban and Regional Studies, vol. XX, pp. 1-18. 